exchanged. In the explanation of the diagram on p. 84 a hair follicle is said to be represented but only a hair is to be seen. It is a pity to use such an expression as "psoriasis of the urethral mucous membrane" when merely some thickened epithelium is present; the expression is clumsy and meaningless. We can speak very favourably of Caspar's treatise in its English dress; it should prove useful to many.

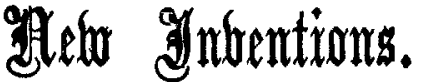

\section{A RUBBING STROP.}

THIs strop, which is made of doeskin, will, I think, be found useful to patients who have to apply liniments with friction to their shoulders and back. 1 have personally found it answer very well in bronchial mischief affecting the

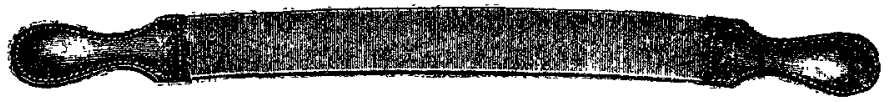

base of the lungs, and I should think it would be serviceable in lumbago. It has been made at my suggestion by Mr. Staniforth, Church-street, Cardiff, and I believe the cost is $3 s .6 d$.

Cardiff.

\section{T. GarRetT Horder.}

\section{A NEW FORM OF RETRACTOR.}

I HAVE designed the retractor illustrated in the accompanying figure more especially to insure an adequate retraction of wounds when assistance is limited. The instrument is, I think, particularly suitable for abdominal work, but I have found it of service in operations on various other regions. It consists of two light steel bars carrying retracting hooks and connected at either extremity by a

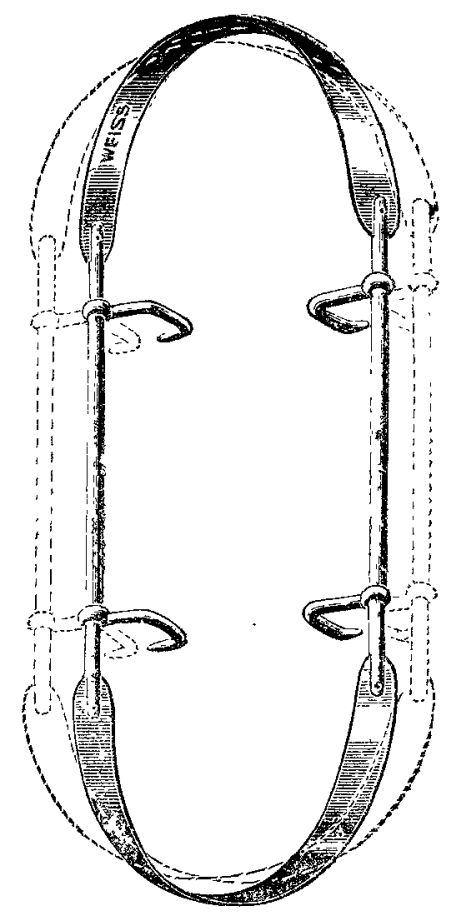

powerful flat steel spring. It has the advantage of being simple, light, easily manipulated, and of securing an adequate exposure while lying entirely out of the field of operation. The three sizes comprising the set have been graduated to be suitable for most operations. The retractor has been manufactured for me by Messrs. Weiss and Sons.

H. TYRRELL Gray.

Hospital for Sick Children, Great Ormond-street, W.C.

\section{A NEW ASEPTIC FUNNEL DOUCHE.}

THE figure shows the form of a new aseptic funnel douche which I have designed and recently shown at the Gynæcological and Obstetrical Section of the Royal Society of Medicine. The advantages of the new douche are as follows. It can be easily cleaned and made aseptic. There is no indiarubber about it to perish; it is durable, being made entirely of metal. It can be easily used by the patient herself in a sitting as well as in a lying position. It can be carried in the ordinary-sized bag. It acts well as a vaginal or a uterine

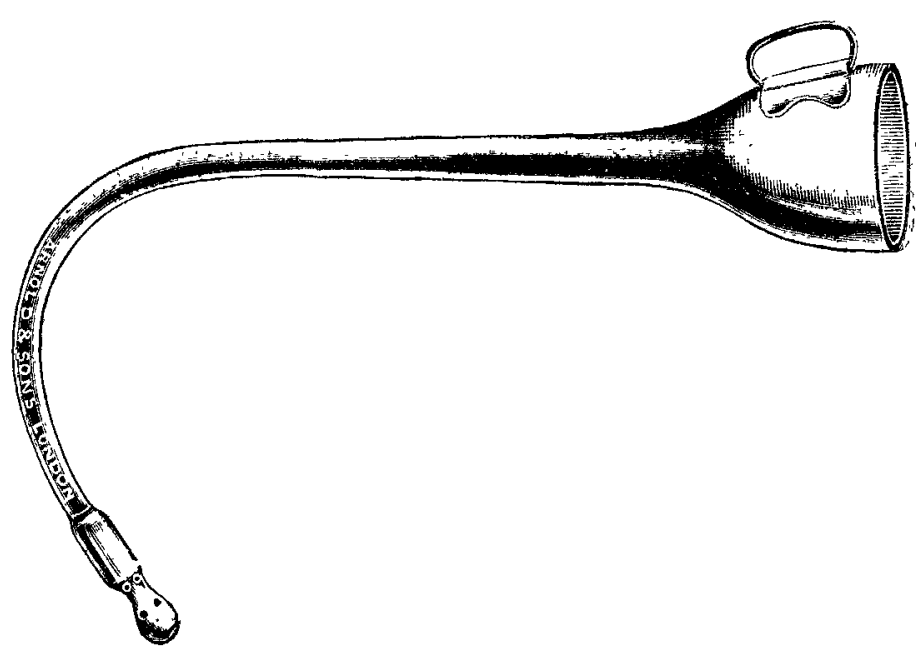

douche and any quantity of the douching liquid can be used It is made in metal, nickel-plated, and is supplied by Messrs. Arnold and Sons, of West Smithfield, London.

Ivydale-road, Nunhead, S.E. ROBERT WISE, M.D. Edin。

\section{NEW FORM OF HYPODERMIC SYRINGE.}

WE have received from Messrs. S. Maw, Son and Sons of 7 to 12 , Aldersgate-street, London, E.C., three samples of a new form of hypodermic syringe which are well worth notice. This type of syringe is called by the manufacturers the "Accosson" hypodermic syringe and three different models are made of it. Of the three samples sent to uss

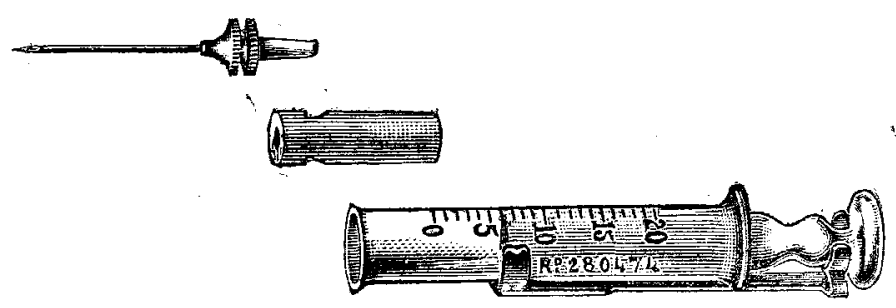

No. 1 is the "Accosson" all-glass syringe, the special feature of which is the glass plug which is so constructed that the needle is coned into the bore of the plug, thus doing away with the delicate glass nozzle over which the needle usually fits. By fitting the needle in this manner there is very little surface exposed to pressure when the syringe is in use and it is therefore almost impossible for the needle to leak or blow off: the price is $6 s .9 d$. No. 2 is the "Accosson" syringe of similar pattern to No. 1, but fitted with a special "sterilite" plug instead of the glass plug; an "Accosson" coned needle fits accurately into the plug and again no leakage is possible. The price is $5 s$. No. 3 is the "Accosson" glass and metal syringe fitted with a "sterilite" expanding plunger. This, the manufacturers claim, is the only perfect expanding. plunger on the market. Certainly it will not stick, and' whether dry or wet is always ready for use. The price is $3 s .9 d$. "Sterilite" plugs and plungers are not in any way affected by boiling and can thus be rendered perfectly aseptic, and no drugs used for hypodermic injections have any effect upon them. The syringes are of English manufacture throughout and the glass used in their manufacture is best English hard flint. The coned needles and the "sterilite" plugs and plungers are valuable modifications of the accepted pattern of hypodermic syringe.

The Dudley Guest Hosprtal.-The annual report presented to the trustees of and subscribers to the above hospital shows increased work with very successful results, increased economy, and increased receipts. The increased support will be particularly welcome inasmuch as in the previous year an adverse balance had to be recorded. During the year the average daily number of beds occupied was 71 . The average stay of the cases was $26 \frac{1}{4}$ days. The average cost per bed was $£ 537 s$. and the average cost per patient $£ 46 s$. $6 d$. In the eye department the average stay was 18 days and the average cost was $£ 37 s .11 d$. 